\title{
Design de Narrativas para Jogos Digitais Baseados em Processos de Negócio
}

\author{
Márcio Rocha Ferreira $^{1}$ e Tadeu Moreira de Classe $^{1}$ \\ ${ }^{1}$ Programa de Pós-Graduação em Informática \\ Universidade Federal do Estado do Rio de Janeiro (UNIRIO) - Rio de Janeiro - RJ - Brasil \\ marcio.ferreiradedu.unirio.br, tadeu.classeduniriotec.br
}

\begin{abstract}
Digital Games Based on Business Processes are a genre of games that represent organizational processes, allowing players to know and reflect on aspects of the process. Narratives are a crucial point for players to understand the game context and the process represented by it. This work proposes a method for generating scripts for these games based on business process models. The research uses the Design Science Research Methodology (DRSM) to conduct it. The evaluation of the proposal will be through qualitative and quantitative approaches, through analysis of data obtained from questionnaires and interviews with the responses of specialists.
\end{abstract}

Resumo. Jogos Digitais Baseados em Processos de Negócio (JDBPN) são um gênero de jogos que retratam processos organizacionais, permitindo que os jogadores conheçam e reflitam sobre os aspectos do processo. As narrativas são um ponto crucial para que os jogadores consigam entender o contexto do jogo e o processo representado por ele. Este trabalho propõe um método de geração de roteiros para estes jogos a partir dos modelos de processos de negócio. A pesquisa usa a Design Science Research Methodology (DRSM) para conduzila. A avaliação da proposta será através de abordagens quali-quantitativas, por meio de análise de dados obtidos de questionários e entrevistas com as repostas de especialistas.

\section{Introdução}

Os jogos com propósito são caracterizados por não ter foco somente no entretenimento, sendo utilizados para transmitir mensagens, ensinar lições e fornecer experiências para seus jogadores [Xexéo 2017]. Estes jogos são utilizados em diversas áreas (ex. educação, saúde, publicidades etc.) [Djaouti et al. 2011]. Um outro cenário de aplicação é no contexto de processos organizacionais, onde jogos podem ser desenvolvidos para promover o entendimento de um processo de negócio [Classe et al. 2019]. Assim, estes Jogos Digitais Baseados em Processos de Negócio (JDBPN) são "um gênero de jogo sério que busca representar um processo de negócio e seus elementos de maneira lúdica, permitindo que ao jogar, os jogadores consigam compreender, treinar, aprender e refletir sobre as características e desafios dos processos organizacionais" [Classe et al. 2019].

Classe et al. (2020), propuseram o método Play Your Process (PYP), com o objetivo de guiar o game designer nas etapas para criação de JDBPN. Todavia, embora o método PYP contemple a etapa de "projeto de jogo", a estrutura narrativa do jogo ainda é pensada de forma ad-hoc, não havendo um suporte à sua criação [Classe et al. 2019]. 
A narrativa é considerada um dos elementos básicos ao game design discutido na tétrade elementar de Schell (2008).

Sendo assim, este trabalho tem o objetivo de estender a etapa de projeto do jogo do método PYP de forma a fornecer suporte para o desenvolvimento de narrativas para JDBPN, através de um método de geração narrativa, semi-automatizada, no qual, a partir de um modelo de processo de negócio, será gerado um metamodelo narrativo. Este metamodelo narrativo servirá como base ao game designer para a construção narrativa do JDBPN.

Visto isso, o presente artigo está organizado da seguinte forma: na Seção 2 é feita a contextualização desta pesquisa na área de Sistemas de Informação. A Seção 3, apresenta a pesquisa como Design Science Research Methodology (DSRM), metodologia baseada na Design Science Research, na qual esta pesquisa se sustenta. E, finalmente, na Seção 4 são apresentadas as atividades realizadas até o momento, os trabalhos futuros e as considerações finais.

\section{Contextualização em Sistemas de Informação}

O estudo de sistemas de informação (SI) envolve, principalmente, as dimensões: organizações, pessoas e tecnologia [Laudon e Laudon 2014]. Uma organização executa as suas atividades com a coordenação de sua estrutura hierárquica, organizada por processos de negócio, desempenhados e gerenciados por pessoas, suportados por recursos disponíveis por meio de uma infraestrutura de tecnologia da informação [Laudon e Laudon 2014]. Neste sentido, analisando os JDBPN, é possível identificar alinhamento desta pesquisa em relação a SIs sob a ótica das três dimensões, considerando a contribuição principal do estudo em cada uma: na compreensão dos processo de negócio da organização (organizações); na colaboração e compreensão dos processos de negócio em que a pessoa participe, interfira ou tenha interesse (pessoas); no design de jogos sérios e engenharia de jogos (tecnologia).

Assim, esta pesquisa se alinha aos GranDSI-BR [Boscarioli et al. 2017], isto porque, dentre os desafios na área de Sistemas de Informação e os Desafios do Mundo Aberto, as organizações querem se abrir para o mundo, e os jogos são um meio possível para isso. O suporte para construção de narrativas é essencial para que os jogadores entendam o jogo, a história e seu fluxo temporal, e com isso, o processo organizacional. Além disso, a pesquisa também se alinha aos GrandDGames-BR, dentro dos desafios propostos por Classe e Araujo (2020), considerando o desenvolvimento de jogos para prover "o entendimento de contextos organizacionais".

\section{Design da Pesquisa e Metodologia}

A pesquisa será conduzida dentro da Design Science Research Methodology (DSRM) e, desta forma, o suporte para design de narrativas será provido através da proposta de um método (artefato principal) e de um software (artefato secundário) que permita sistematizá-la, envolvendo desde a extração dos elementos da narrativa a partir de modelos de processos de negócio, até a estrutura de roteiro para o jogo.

As etapas da DSR serão realizadas de forma iterativa, onde após avaliação de cada iteração, o projeto e/ou solução é ajustado para uma nova iteração [Pimentel et al. 2020]. A Figura 1 apresenta um diagrama baseado no DSRM representando os elementos desta pesquisa. 


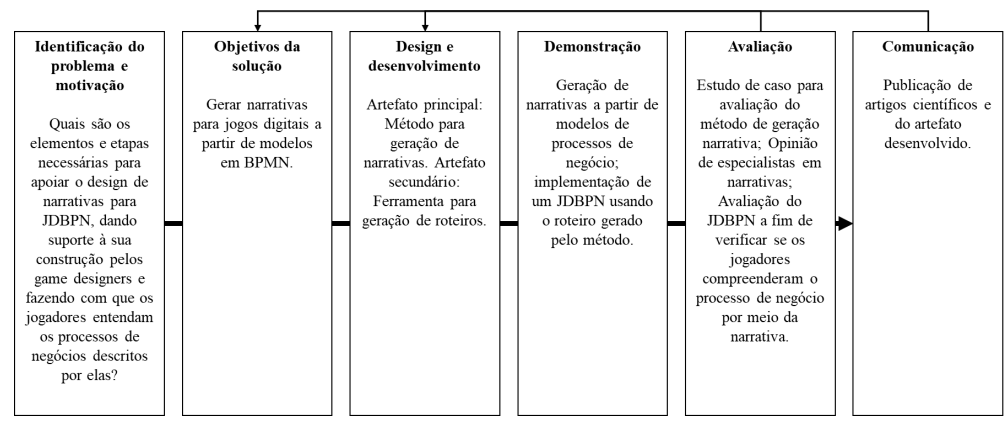

Figura 1. Design da pesquisa (Adaptado de [Peffers et al. 2007])

\subsection{Identificação do Problema e Motivação}

O design de JDBPN deve observar as atividades, eventos e regras de um determinado processo de negócio, para que eles possam retratar o processo de negócio de forma mais fiel possível [Classe et al. 2019]. Neste contexto, o método Play Your Process (PYP) visa guiar os game designers, incluindo formas de mapear elementos BPMN a elementos do gênero de jogo, e até a construção do jogo [Classe et al. 2019].

Um elemento de jogo que permite os jogadores entenderem o mundo do jogo, seus objetivos e se imergirem é a narrativa [Rogers 2010]. As narrativas também são usadas em Gestão de Processos de Negócio, como forma de facilitar o entendimento do processo aos stakeholders [Dumas et al. 2013]. Sendo assim, surge o problema de projetar narrativas aos jogos de modo que elas sejam fieis aos elementos do processo.

Os trabalhos de Antunes et al. (2019) e Juchova et al. (2010) utilizaram storyboards para representar modelos de processos de negócio, porém os métodos não provêm roteiros textuais. Neste sentido, o problema que esta pesquisa visa investigar é: Quais são os elementos e etapas necessárias para apoiar o design de narrativas para jogos baseados em processos de negócios, dando suporte à sua construção pelos game designers $e$ fazendo com que os jogadores entendam os processos de negócios descritos por elas?

\subsection{Proposta de Solução}

A proposta de solução envolve a definição de um método para geração de roteiros para JDBPN a partir de modelos de processos de negócio. O método será composto por 4 etapas (2), tendo apoio de um artefato de software para automatizar a geração de uma estrutura de roteiro preliminar, artefato este responsável por dar suporte às duas primeiras etapas.

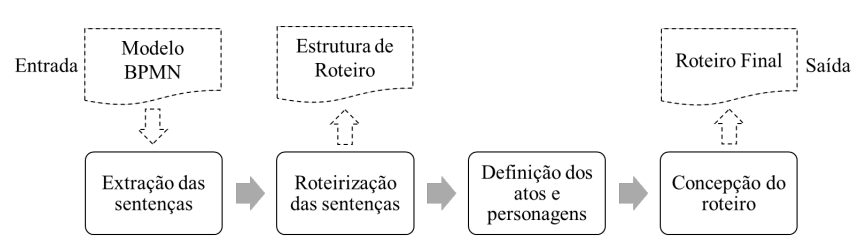

Figura 2. Etapas para Geração do Roteiro para JDBPN

Portanto, nestas primeiras etapas, a extração de sentenças objetiva formar frases que representem eventos, atividades e gateways do BPMN, obedecendo o formato: [sujeito] + [verbo] + [complemento]. O sujeito é o ator responsável (lane) pela realização do evento, atividade ou gateway. Um verbo é escolhido em função do tipo de elemento 
BPMN para indicar a ação do sujeito sob o complemento. Já o complemento corresponde ao próprio elemento, podendo estar associado a recursos (resources) do BPMN. Com as sentenças criadas, é possível estruturá-las em um roteiro, uma vez que o próprio modelo de processo representa sequência de acontecimentos temporais, tal qual uma narrativa.

As duas etapas seguintes referem-se ao trabalho criativo do roteirista e não devem ser automatizadas, já que a criatividade é imprescindível em um trabalho de narrativas para jogos. Além disso, a estrutura de roteiro gerada não possui as características lúdicas do jogo ainda, sendo apenas um resultado da roteirização das sentenças obtidas automaticamente do modelo do processo de negócio.

\subsection{Demonstração e Projeto de Avaliação da Solução}

Para demonstrar a solução proposta, será necessária a realização de estudos de caso com game designers para verificar se o modelo proposto é viável na geração dos roteiros dos jogos. Após isso, a avaliação ocorrerá por meio de entrevistas e questionários aplicados a game designers para obter suas opiniões, pontos fortes e fracos do método e como melhorá-lo. Os dados serão analisados qualitativamente a fim de gerar novas versões do método, dando início a novos ciclos de design, já previstos na DSR. Além do método, a ferramenta de sistematização destes roteiros será avaliada usando o método TAM (Technology Acceptance Model) [Davis 1986] com a participação de voluntários que irão julgar a utilidade, facilidade e intenção de uso.

Também é necessário avaliar se o artefato realmente é eficaz, se é fácil de usar, assim como se a narrativa gerada facilitou a compreensão do processo de negócio e se o representou de forma adequada. Para isso, será pensado e desenvolvido um JDBPN, e o mesmo será avaliado com gestores do processo e público-alvo para validar se a narrativa apresentada contempla o processo de negócio encenado pelo jogo.

\section{Considerações Finais}

Este trabalho visa propor um método para geração de narrativas para JDBPN. O método visa prestar o suporte para os profissionais envolvidos na criação dos roteiros dos jogos, sem limitar a criatividade deles. O método terá também uma ferramenta para apoiar as etapas, onde, a partir de um modelo de processo de negócio, deve gerar um roteiro narrativo preliminar. Desta forma, o profissional de game design não precisará ter domínio sobre diagramas, notações e representações de processos de negócio.

As seguintes contribuições são esperadas com esta pesquisa: i) disponibilização de meio para análise e entendimento de processos de negócio pelas partes interessadas (clientes, colaboradores e/ou sociedade); ii) criação de solução para geração de roteiros narrativos sobre processos de negócio a partir de seus respectivos modelos; iii) criação de sistema de geração de narrativas para o método PYP e para desenvolvimento de JDBPN.

As atividades realizadas dentro do escopo da pesquisa até o presente momento foram: mapeamento sistemático da literatura envolvendo os temas "narrativas" e "gestão de processos de negócio"; caracterização da pesquisa e definição do produto; e uma primeira versão do método para extração de sentenças e geração de narrativas para JDBPN.

Os trabalhos futuros da pesquisa são: refinamento do método a partir de provas de conceito; desenvolvimento do artefato de software; design de um JDBPN e comunicação dos resultados (artigos, relatórios etc.). 


\section{Referências}

Antunes, P., Pino, J. A., Tate, M., e Barros, A. (2020). Eliciting process knowledge through process stories. Information Systems Frontiers, 22(5):1179-1201.

Boscarioli, C., Araujo, R. M., e Maciel, R. S. P. (2017). I GranDSI-BR - Grand Research Challenges in Information Systems in Brazil 2016-2026. Brazilian Computer Society (SBC).

Classe, T., Siqueira, S., Araujo, R., e Xexéo, G. (2020). Play your process - um método de design de jogos digitais baseados em modelos de processos de negócio. In Anais Estendidos do XVI Simpósio Brasileiro de Sistemas de Informação (SBSI 2020), pages 142-157, Porto Alegre, RS, Brasil. SBC.

Classe, T. M. e Araujo, R. M. (2020). Jogos como plataformas mediadoras em um mundo aberto e digital. Simpósio Brasileiro de Games e Entretenimento Digital (SBGames), pages $1131-1134$.

Classe, T. M. d., De Araujo, R. M., Xexéo, G. B., e Siqueira, S. (2019). The play your process method for business process-based digital game design. International Journal of Serious Games, 6(1):27-48.

Davis, F. (1986). A technology acceptance model for empirically testing new end-user information systems: theory and results. PhD thesis, MIT Sloan School of Management, MIT Sloan School of Management.

Djaouti, D., Alvarez, J., Jessel, J. P., e Rampnoux, O. (2011). Origins of serious games. In Ma, M., Oikonomou, A., e Jain, L. C., editors, Serious Games and Edutainment Applications, pages 25-43. Springer London.

Dumas, M., La Rosa, M., Mendling, J., e Reijers, H. A. (2013). Fundamentals of business process management. Springer.

Juchova, V., Stolfa, S., Ježek, D., e Vondrak, I. (2010). Storyboards in business process modeling. In 8th International Industrial Simulation Conference (ISC 2010).

Laudon, K. C. e Laudon, J. P. (2014). Sistemas de Informação Gerenciais. Pearson, 11. edição.

Peffers, K., Tuunanen, T., Rothenberger, M. A., e Chatterjee, S. (2007). A design science research methodology for information systems research. Journal of Management Information Systems, 24(3):45-77.

Pimentel, M., Filippo, D., e Santoro, F. M. (2020). Design science research: fazendo pesquisas científicas rigorosas atreladas ao desenvolvimento de artefatos computacionais projetados para a educação. In Concepção de Pesquisa, Metodologia de Pesquisa em Informática na Educação. SBC.

Rogers, S. (2010). Level up! the guide to great video game design. Wiley.

Schell, J. (2008). The art of game design: a book of lenses. Elsevier/Morgan Kaufmann.

Xexéo, G. (2017). O que são jogos - uma introdução ao objeto de estudo do ludes. Relatório Técnico do LUDES RT LUDES 2017-01, Universidade Federal do Rio de Janeiro, Rio de Janeiro (UFRJ). 